\title{
EL SIMBOLISMO EN LA PINTURA SEVILLANA (1880-1938)
}

\author{
por Gerardo Perez Calero
}

\begin{abstract}
En el presente trabajo se aborda de forma sintética el rico panorama del Simbolismo, como movimiento o tendencia artística de fines del XIX y primer tercio del actual sobre la Pintura sevillana. Para ello se pasa revista a los mas representativos pintores hispalenses del momento que cultivan las dos variantes, cuadro religioso y profano; como son, entre otros, Jiménez Aranda, Mattoni de la Fuente, Gonzalo Bilbao, etc. Todos ellos muestran los característicos efectos fantásticos en los que la alegría constituye la esencia de la obra con matices muy singulares de subjetividad y decorativismo.
\end{abstract}

This article adopts a synthetic approach to the wide spectrum of Symbolism, as a movement or artistic trend of the late 19th and early 20th centuries, and its influence on Sevillian painting. It examines the most representative Sevillian painters of the period who cultivated the two forms, religious and profane painting: artists such as Jimenez Aranda. Mattoni de la Fuente, Gonzalo Bilbao and others. All of these painters display the same characteristic fantstic elements, with allegory forming an essential part, overlaid with striking nuances of subjetivism and decorativism.

«En memoria de mi amigo y compañero Bernardino de Pantorba, estudioso de la Pintura sevillana».

Sin ánimo de agotar tema tan sugestivo y al tiempo complejo, al que deseo dedicar futuros trabajos, acometo en ésta ocasión el estudio sobre algunos matices del Simbolismo pictórico hispalense, con la intención de dejar planteado, si acaso sucintamente, sus líneas fundamentales en la etapa arriba senalada.

De amplia difusión en algunos paises europeos, especialmente Francia y también Inglaterra, el Simbolismo, además de una constante artística, es un amplio movimiento cultural que afecta más específicamente a la Literatura y artes plásticas y sobre el que van a discurrir buena parte de las tendencias pictóricas del continente en torno al último cuarto del siglo XIX y primero del presente. 
En Sevilla, algunos pintores nacidos en los comedios del siglo se sentirán sensibilizados en tierra tan dada a meditar sobre la trascendencia de la vida y a plasmar en imágenes más o menos poéticas actitudes y conductas trascendentales o aún cotidianas que se convierten en símbolos de su propia idiosincrasia. Mas esta actitud, llevada a cabo apenas por media docena, los más cultos, obedece a una iniciativa personal de talante subjetivo motivada por su contacto con los movimientos artísticos europeos, especialmente el fenómeno simbolista, a través de los medios de difusión de imágenes gráficas (revistas de diseños, de decoración, dibujos de artes y oficios, etc.) que daban a conocer las novedades presentadas sobre todo en los salones parisinos y en los numerosos certámenes convocados por las asociaciones artísticas de la capital del Sena, sin olvidar las exposiciones universales de 1878, 1889 y 1900. También hay que tener en cuenta el contacto de los simbolistas sevillanos con el ambiente catalán por la venida a la capital andaluza de algún arquitecto o artista de ésta procedencia. Ninguno de aquéllos artistas hispalenses a los que nos referiremos más adelante, visitó Francia o Inglaterra estando en auge el movimiento - pues José Jiménez Aranda estuvo en París un año después de ralizar en 1880 su primera obra simbolista conocida - pero sus inquietudes les llevaron a la búsqueda de semejante estética novedosa en el ambiente de la capital del Betis. Todos ellos cultivan habitualmente otras variedades pictóricas: el paisaje, el cuadro de género y el retrato, por lo que puede decirse que se entregan a las representaciones simbolistas de manera fugaz y con matices muy singulares que hace aun más interesante en ellos esta modalidad artística.

No existe en rigor un programa iconográfico previo en estos pintores sevillanos cultivadores de un simbolismo muy desigual tanto en intencionalidad temática como en su factura formal, pero a todos les une un afán claro de plasmar ideas subjetivas y sintéticas con cierto grado de decorativismo que a veces parecen relacionarse con un Modernismo que les es próximo estéticamente. Todos ellos ven en el Simbolismo ciertos ecos románticos que les evoca de algún modo un pasado relativamente próximo (la pintura de varias décadas antes) o remoto (determinada conexión, a veces solo formal, con el Barroco pictórico) pero casi siempre advierten en ésta tendencia una oposición al Realismo como propiciador, con su objetivación plástica, de la pérdida de los valores ideistas trascendentes. En consecuencia, en una época en la que las tendencias artísticas se suceden casi simultáneamente, algunos de los pintores objeto de éste estudio llegan, en natural evolución, al cuadro de realismo social (de «tesis»), cuyo valor simbólico mantiene de algun modo.

El simbolismo en la pintura sevillana, pese a la ya aludida complejidad que manifiesta en la etapa que nos toca estudiar, influye simultáneamente sobre la temática religiosa y sobre la que podríamos llamar alegórico-profana. Por consiguiente, pasaremos a analizar los rasgos más característicos de cada una de ellas y los pintores que cultivan ambas variantes. 


\section{EL SIMBOLISMO EN LA PINTURA RELIGIOSA HISPALENSE}

Durante el siglo XIX es manifiesta la decadencia de la pintura religiosa en España tras el auge que había tenido en las centurias anteriores. Este decaimiento - para algunos auténtica crisis - ${ }^{1}$ tiene múltiples razones, entre otras, la escasa protección de que disfrutaban nuestros pintores, junto al olvido de la tradición española; así como por el auge de las Exposiciones Nacionales que redundó en su perjuicio. Por fin, y sobre todo, la falta de estímulos ambientales para cultivar un género no sentido ya por los pintores, más dados a realizar cuadros de historia, de género o paisajes.

El progrsivo abandono del cuadro religioso se va haciendo cada vez más patente a medida que avanza la centuria, volviéndose crítico al iniciarse la siguiente, en la que la filosofía, la ciencia y la técnica constituyen las verdaderas preocupaciones del hombre moderno y por ende del artista. Sin embargo, si éste es el panorama general del género religioso en España, muy especialmente fomentado por los círculos artísticos oficiales de la capital del reino y otras escuelas más progresistas en materia artística, no puede decirse lo mismo de Sevilla, en donde el ambiente más conservador propiciaba la actividad, al menos en los sectores más influyentes, del arte religioso en general - piénsese lo que supone la permanencia durante todo el Ochocientos de una pujante imagineria religiosa que mantiene abiertos talleres de escultura herederos muchos de ellos de los más reputados del Barroco- ${ }^{2}$. O en el simbolismo de Valdés Leal en La Caridad.

La pintura religiosa $\multimap$ de tema religioso- en el ambiente artístico sevillano del último cuarto del Ochocientos y primer tercio del Novecientos cultivará asuntos de una particular devoción, que apelen al sentimiento con abundante carga lírica y en los que con frecuencia se puedan mezclar poesia y pintura como denominador común de lo religioso, lo que predispone al autor a un cierto intelectualismo no apto para el espectador medio-bajo, de ahí que esta clase de obras surjan por un determinado interés personal del artista, o bien por un encargo especial de una clientela distinguida.

José Jiménez Aranda (1837-1903) es el primero que generacionalmente y sin sentir la llamada del género religioso imprime caracteres simbolistas a determinadas obras religiosas; tal es el caso y en primer lugar del tríptico $L a$ visión de Fray Martín, realizado en Sevilla en 1880 y exponente de los valores de su autor como creador plástico de escenas poético-simbolistas. En efecto, tal como hiciese Odilón Redón con las litografías para ilustrar La tentación de San Antonio, de Flaubert, el pintor sevillano, basándose en los tres cantos del poema del mismo título del vallisoletano y coetáneo Gaspar Nuñez de

1. Alvarez Lopera, J. «La crisis de la Pintura religiosa en la España del siglo XIX». Cuadernos de Arte e Iconografía. Tomo I. N. ${ }^{\circ} 1$. Madrid, 1988. Pág. 81 a 120.

2. Banda y Vargas, A. de la. «La imaginería procesional sevillana en los siglos XIX y XX». Consejo General de Hermandades y Cofradías de la Ciudad de Sevilla. Sevilla, 1980, s/p. 
Arce (1834-1903), nos muestra en un derroche de ingenio sendos dibujos a la «gouache», de $50 \times 32$ (col. part.) con otras tantas escenificaciones ricas en valores iconográficos que recuerdan de modo ecléctico enseñanzas aprendidas en el Barroco por el empleo de amplios escenarios, apoteosis barrocas cargadas de dinamismo e ímpetu en los que usa recursos muy expresivos como la perspectiva oblicua, el claroscuro y otros efectos para aumentar el simbolismo fantástico mediante el que quiere expresar algo tan abstracto como los problemas de conciencia del fraile reformador ${ }^{3}$.

Acometió también Jiménez Aranda varios asuntos relativos a la pasión de Cristo, en los que se hacen presentes las características del simbolismo mas agudo y expresivo. Tal es el caso de los cuadros titulados: La Oración en el Huerto (66x54. Prop. part.); El Prendimiento de Cristo (60x50. Pro. part.); De Herodes a Pilatos (59x49. Prop. part.); El Calvario (varias versiones) y Consumatum est, gran lienzo de $236 \times 145 \mathrm{~cm}$., actualmente en la capilla de la Hispanic Society of América (New York). Este último representa a Cristo muerto en la cruz envuelto entre vaporosas y espectaculares nubes, divisándose a lo lejos un fondo de paisaje de difícil identificación por sus vagos caracteres. La obra presenta, finalmente, fuertes rasgos expresivos propiciados por la pobre gama cromática que se emplea y, como en el caso anterior, por los efectos de luces y sombras.

De una generación posterior y coetáneo de Odilón Redón, Virgilio Mattoni de la Fuente (1842-1923) es, sin duda, el más interesante pintor religioso de la escuela sevillana cultivador de un peculiar simbolismo personal emanado de su fuerte intelectualismo, así como por su predisposición poética en la que hay que buscar ciertas afinidades con los modernistas. A este respecto, se conocen algunas composiciones poéticas en las que patentiza su sentida religiosidad que, pletórica de misticismo, llega a convertirse en una casi exaltación lírica en la que no está exenta también la influencia seráfica, por su relación personal con los Capuchinos de Sevilla. Como un poeta simbolista, Mattoni habla del «Pasajero», en los siguientes términos ${ }^{4}$ :

«Respeta de este prado las florecillas tiernas;

yo te diré la historia de un capullo

de tan triste y efímera existencia

que ni rompió su tallo damasquino

ni vio la primavera.

3. Pérez Calero, G. José Jiménez Aranda. Col. «Arte Hispalense». N. ${ }^{\circ} 29$. Sevilla, 1982. Pág. 33, 136 y 140 .

4. Pérez Calero, G. El pintor Virgilio Mattoni. Col. «Arte Hispalense». N. ${ }^{\circ}$ 15. Sevilla, 1977. Pág. 28 y 29 . 


\begin{abstract}
Alzaba aquel capullo hasta los cielos, su corola sedienta.

Si orar saben las flores, rezando estaba aquélla.

La mano alabastrina de una gentil doncella la arrancó de su tallo en los albores de su triste y efímera existencia, la acercó un momento a sus labios, y después acercó a otra flor los labios de ella.

Así la florecilla perdió el recato y su falda regia y exhalando a los vientos tantos ayes, como hojas se escapaban de su vista, exaló su suspirillo, ¡ay!, y quedó muerta».
\end{abstract}

De la misma manera se dirige al «hermano árbol» de este modo:

«Era una tarde plácida, ¿Te acuerdas?, bajo tu toldo de hojas, pintadas por las luces del otoño, de tintas amarillas, verdes, rojas...

Estaban nuestros cuerpos, dos cuerpos cauces de rugientes olas; él sereno el semblante y la palabra pronta, nos reveló el secreto de su vida rasgando un velo de azulada sombra.

Fue tan triste el secreto y tan grande la pena ¡ay Dios! tan honda, que tu copa abatióse y me dijo, iperdona! De aquel secreto triste que ignore el mundo la doliente historia.

Es la vida de un alma, por buena, quizás loca.

Yo le diré a la tierra cuando expire..., dísela tu a los cielos con tu copa!».

Finalmente, en el poema: «Plegaria de un artista el primer día del año», el pintor comienza hablando de la «modestia» como un valor ético inmerso en una filosofía próxima a la del simbolista francés Odilon Redon (18401916), del que también se mantiene en paralelo en las composiciones anteriores por su valoración contemplativa del entorno natural: 
«La modestia, Señor, mis pasos guien.

Ella es la antorcha luminosa y clara

con que el ajeno viento adivinábamos

contemplando a la vez nuestra ignorancia.

$\mathrm{Y}$ al terminar el año que hoy comienza, tranquilo a tí levanto la mirada, sin que la negra sombra de la culpa la estrella eclipse a mi dulce calma.

¡Soberano hacedor!, ¡Padre clemente!, tierno acoge y propicio, mi plegaria; no te pido otro bien si fiel te sigo...

¿Qué más ventura que la paz del alma?

En 1891 fecha el pintor Mattoni una de sus primeras obras religiosas simbolistas: El Salvador (6́leo sobre lienzo. 80x35 cm. Prop. part.). Representa a Cristo vestido con túnica blanca y manto rojo con los brazos abiertos y los estigmas en sus manos ante una escalera en cuyos peldaños hay flores esparcidas. Tras él aparece un fuerte resplandor que hace desaparecer casi misteriosamente el fondo de la composición. El cuadro encierra en sí la idea simbólica de la representación de la soledad y caridad de Cristo, entregado a los demás por amor.

La iconografía del Sagrado Corazón de Jesús inspira al pintor sevillano en una serie de representaciones en las que se acusan al propio iempo valores decorativos que las acercan a un atractivo modernismo muy personal ${ }^{5}, y$, casi insensiblemente, a un prerrafaelismo simbolista, acorde, muchas veces, al ambiente artístico e incluso arquitectónico que rodea a la obra. Este es el caso de algunas de ellas que incluso llega a identificar iconográficamente con el tema de Cristo Rey.

En la Capilla del Sagrado Corazón de la iglesia parroquial de San Andrés de Sevilla, decorada bajo la dirección de Mattoni en 1893 y en la que interviene como colaborador el escultor Adolfo López Rodríguez, el pintor hace gala de su conocimiento del muralismo, sin duda aprendido en el conjunto medieval de San Isidoro del Campo, en Santiponce, cuyas copias verificó siendo muy joven $(1868)^{6}$. Despliega toda suerte de figuras y elementos ornamentales inspirados en una sofisticada estética medieval a base de pavimento en ajedrezado, decoración epigráfica, entrelazos, dientes de sierra, etc. ${ }^{7}$.

5. La relación de Mattoni con el Modernismo, no claramente delimitada, llega a convertirse casi exclusivamente en una oposición verbal al mismo, toda vez que, pese a calificarle como «frío cálculo y sistemático escepticismo», llega a emplear, como se está viendo y volveremos a comprobar mas adelante, elementos afines al mismo. Vid. mi monografía sobre el pintor recogida en la nota anterior.

6. Pérez Calero, G. Op. cit. en nota 4. Pág. 36. 
La escena principal la constituye un tímpano, en cuyo centro se muestra entronizado el Sagrado Corazón de Jesús representado iconográficamente como Cristo Rey que porta en su mano derecha el cetro del poder ofreciendo abierta la contraria. A su derecha aparece representado el jesuita vallisoletano padre Hoyos, ferviente devoto de la imágen de Cristo Rey; y a la izquierda la religiosa de la Visitación, Margarita María de Alacoque, canonizada en 1921 y famosa por sus revelaciones que tanto han contribuido a fomentar la devoción al Sagrado Corazón de Jesús.

Acompañan a la representación principal sendos ángeles elegantísimos por su estilización y esbeltez, rubios, vestidos con amplias casullas ricamente recamadas con escudos, portadores de cintas o filacterias con leyendas epigráficas que relatan fragmentos de capítulos y versículos del evangelista Mateo. Uno de ellos, además, porta entre sus manos un gran ramo de flores, otro elemento simbólico. Ambos están ejecutados al modo de tablas medievales, con gran pormenor y tratamiento exquisito, acusándose en sus semblantes un cierto aire boticceliano, cual si de personajes del Rossetti prerrafaelista se tratase.

Unos años después (1915) realiza Mattoni para el Colegio granadino del Sagrado Corazón una tabla $(300 \times 200 \mathrm{~cm}$.) con destino al retablo principal de su capilla de arquitectura neogótica. En esta ocasión el pintor situa de pie en el centro la representación de Cristo como Rex Regum, portando corona real y mostrando su Corazón. Delante y a ambos lados se situan de izquierda a derecha respectivamente, San Juan Evangelista mostrando abierto el Libro de los Evangelios y la bienaventurada Sofia Magdalena.

Siguiendo con ésta iconografía neomedieval de evocaciones bizantinizantes cargadas al propio tiempo de connotaciones simbolistas, Mattoni realiza varias tablas amorosamente repujadas y de resultado primoroso según procedimiento antiguo, de tal modo que, como él mismo dice, «renovó en Sevilla el estilo arcaico de los primitivos y quincentistas» ${ }^{8}$. Una de ellas, fechada en 1897 (100x80 cm. Catedral de Sevilla) representa la Anunciación en bellísima y sofisticada escenificación que tiene como marco una estancia abierta por el fondo que a modo de ventanal-parteluz permite ver, por el espacio que deja la cortina corrida, un paisaje cargado de efectismo por su luminosidad, que anuncia un radiante y plácido amanecer. Su simbolismo evoca también algunas representaciones de Rossetti, especialmente por su candor y lirismo. Hasta las azucenas, símbolo de la pureza de María, tienen aquí, como en los lirios de los poetas simbolistas, todo su valor íntimo y entrañable.

A semejanza de la anterior y probablemente de las mismas fechas es la tabla inconclusa que representa un Desposorio místico (120x63 cm. Prop. part.), cargada igualmente de elementos simbolistas que juegan armoniosamente con

7. Acerca de la labor conjunta de Mattoni y Adolfo Lopez en esta estancia, vid.: Serrano y Ortega, M. La Capilla del Sagrado Corazón de Jesús de San Andrés. Sevilla, 1884. Imprenta del Obrero de Nazaret.

8. Mattoni de la Fuente, V. «Sevilla en sus pintores». Quien no vió Sevilla... Sevilla, 1920. Pág. 154. 
el decorativismo que crea la minuciosa técnica empleada por el pintor, quien en estas tablas se comporta cual si de un orfebre o miniaturista se tratase, pues emplea un concienzudo dibujo previo propio del diseño artesanal o industrial? .

De la misma fecha que las anteriores, son dos obras que se hallan en el templo de San Alberto de Sevilla representando La huida a Egipto y Cristo por la Calle de la Amargura. Ambas también poseen un peculiar simbolismo con matices pintorescos, especialmente la última, en cuyos personajes pueden verse gestos y actitudes declamatorios muy del gusto del movimiento estético prerrafaelista.

Otros cuadros religiosos del mismo artista tienen igualmente un marcado acento simbolista. Tal es el caso de algunos de temas hagiográficos. El mas antiguo conocido (1895) representa a Santa Isabel de Hungria (tabla de 157x38 $\mathrm{cm}$. Templo de Capuchinos de Sevilla) que aparece en una estancia palaciega portando la corona regia y manto ricamente recamado. Al fondo se divisa la torre de agudo chapitel correspondiente a un edificio noble, siendo el mismo que aparece en la tabla de la Anunciación ${ }^{10}$.

También para la iglesia del convento de Capuchinos de Sevilla realiza Mattoni un San Francisco de grandes dimensiones y en lienzo (200x100), al que representa con los brazos extendidos, los estigmas en manos y pies, en plena levitación e iluminado con destacado efectismo por un gran farol que se halla a sus pies.

De pequeñas dimensiones es, en cambio, su Santa Apolonia (30x25. Prop. part.) a la que representa con su habitual iconografía, es decir, con la bandeja en que porta los dientes y junto a la hoguera de su martirio.

Finalmente, dentro de este capítulo y como alegoría festivo-religiosa, conviene incluir la composición que, fechada en 1919, representa El Corpus y la Inmaculada, reproducida en el libro Quién no vio Sevilla... (pág. 201). Se trata de un dibujo de $85 \times 16$, que escenifica a dos Seises, vinculados respectivamente a cada festividad, portando en ambas manos un jarrón de azucenas, al tiempo que se divisa al fondo la Custodia de Juan de Arfe de la catedral hispalense.

El ambiente de desasosiego en que vive la sociedad española a fines de siglo -recogido en sus inquietudes por la Generación del 98- como reflejo a su vez de lo que está sucediendo en Europa y cuyo desenlace llevaría a la Primera Guerra Mundial, influye de forma especial en una suerte de simbolismo

9. Hay que tener en cuenta la importancia cada vez mayor que van adquiriendo en su época las artes y oficios y el điseño industrial. En este sentido conviene advertir como va a cambiar la denominación de los tradicionales centros de enseñanzas artísticas, que comenzarán a llamarse Escuelas de Artes e Industrias Artísticas, y, con el tiempo, Escuelas de Artes Aplicadas y Oficios Artísticos.

10. Esta obra de Mattoni es simultánea con su petición al Gobierno de la Nación del título de Santa Isabel de Hungría para la Real Academia de Bellas Artes de Sevilla. Vid.: Pérez Calero, G. «Virgilio Mattoni y las Corporaciones Artísticas sevillanas». Boletín de Bellas Artes. N. IV. Sevilla, 1976, pág. 189. 
personal del tambien sevillano José Villegas y Cordero (1844-1921). Su Decálogo, ejecutado entre fechas tan significativas como 1898 y 1914, es -según sus propias palabras - «eco sonoro de sentimientos y pasiones que brotaron del alma del artista; un valor espiritual que se lanza al combate esperando hacer vibrar las conciencias atormentadas por la congoja de esta hora trágica. Es una obra en la que como en la vida, el bien surge del mal. Si consigo que la sensibilidad delicada y expresiva que anida en ella se transmita a todo expectador a través de diversas gradaciones de cultura, habré realizado mi ensueño evocador de un ideal que nos purifique del positivismo y escepticismo del presente» ${ }^{11}$.

El Decálogo sintetiza, como dice su autor, los méritos mas expresivos del Simbolismo como movimiento artístico que propugna los valores del espíritu frente a la materia. Viene a ser una estética redentora de las conciencias atormentadas en la búsqueda de un ideal. Obra tan ambiciosa tanto por su complejidad temática como por su intencionalidad iconográfica, despertó vivo interés en los ambientes intelectuales de una Sevilla dividida entre entusiastas de las «nuevas» corrientes estéticas, progresistas artísticamente hablando, y partidarios de las tradicionales formas puristas mas o menos académicas. De este modo, se entablaron auténticas batallas dialécticas, orales o escritas, entre miembros del clero sevillano separado a la hora de enjuiciar la obra, pese a quienes consideraban que fue sugerida por el propio Papa León XIII ${ }^{12}$. Para unos, fue considerada de la mas pura ortodoxia y, para otros, entendida como ejemplo teosófico-masónico. Estos últimos constituían un grupo de intelectuales que no supieron comprender - por carecer de los específicos conocimientos artísticos- la auténtica intención de su simbolismo religioso ${ }^{13}$.

Los verdaderos fundamentos acerca de tan acalorada polémica sobre la obra de Villegas estribaban en la consideración por algunos de su heterodoxia, relacionándolo con la Rama Fraternidad de la Sociedad Teosófica de Sevilla, una de cuyas veladas se hizo pública por la prensa. Fue la correspondiente al 24 de noviembre de $1916^{14}$ en la que el presidente de la asamblea dirigió cariñosas frases de saludo y encomio al pintor, presentándolo a los demás asistentes y haciendo a continuación vivas consideraciones acerca de la importancia que para la propaganda de las ideas teosóficas tiene su Decálogo. Interviene después el propio artista, agradecido por el homenaje, explicando

11. Cuenca, Francisco. Museo de Pintores y escultores andaluces contemporáneos. La Habana, 1923, pág. 388.

12. Olmedo Sánchez, M. «El Decálogo de Villegas». «A.B.C.». Sevilla, nov. 1974.

13. Tal es el caso de la polémica llevada a cabo entre los presbíteros e intelectuales sevillanos, Serrano Ortega y Federico Roldán, defensores respectivamente de la heterodoxia de la obra y de la ortodoxia de la misma. Verdadera diatriba que tuvo como vehículo varios opúsculos publicados por ambos a sus expensas y también a través de los diarios de prensa local, especialmente «El Liberal». Vid.: Serrano Ortega, M. La teosofía en el Decálogo de Villegas. Sevilla, 1917. Roldán, Federico. El Decálogo de Villegas en su expresión ideológica. Sevilla, 1917.

14. «El Liberal». N. ${ }^{\circ} 5725$. Sevilla, 25/11/1916. 
su obra como propia del simbolismo, pues cada tono, cada figura, cada detalle o signo que para el vulgo pasa desapercibido, es el simbolo de una idea teosófica.

La obra -reconoce su autor- está inspirada en muchos aspectos de la literatura simbolista, especialmente la francesa; así, entre otros en el pensamiento literario de Amado Nervo (1870-1919), poeta mexicano, contemporáneo de Rubén Darío y afín a sus ideas. Villegas y Nervo se conocieron en Madrid, cuando el primero dirigía el Museo del Prado, estableciéndose entre ambos una relación artística como acreditan el simbolismo del Decálogo y el espíritu que inspirara «La Revista Moderna», fundada por el mexicano y Jesús E. Valenzuela.

En los doce cuadros que componen el Decálogo ${ }^{15}$ su autor introdujo toda suerte de elementos simbolistas que hacen que las escenas representadas se llenen de énfasis espiritual: velos transparentes que ondean al viento, halos resplandecientes sobre los personajes, ruedas centelleantes, arcos, círculos y triángulos concéntricos, manos humanas que proyectan radiante luz de sus dedos, etc. Es fantasía hecha pintura.

El último por generación de los pintores sevillanos en el cual también incide el Simbolismo religioso es Gonzalo Bilbao Martínez (1860-1938), autor de los medios puntos realizados en 1902 (320x248. Protectorado de la Infancia de Triana), en los que efectúa dos escenificaciones marianas de hondo contenido místico-espiritual y llenas de fantasías simbolistas: Regina Virginum, es la primera. Representa a la Virgen niña rodeada de jóvenes santas y profesas. Las primeras situadas a su altura y en disposición isocefálica llevan resplandecientes nimbos sobre sus cabezas. Las jóvenes profesas, separadas de aquéllas por varios escalones llenos de flores, tienen ante si un jarrón de azucenas sobre una alfombra roja cubierta de flores del mismo color. Todo ello de gran suntuosidad simbolista.

La segunda representación mariológica de Bilbao, Stella Matutina, muestra el mismo modelo de Virgen en iconografía asuncionista, cubierta la cabeza con amplísimo y sutil velo, con los brazos cruzados sobre el pecho y una estrella resplandeciente sobre su cabeza, en el momento de ascender a los cielos de Sevilla que aparece iconografiada al fondo y de la que destacan, en primer término Triana y el Río, a lo lejos la catedral con la Giralda y la Torre del Oro $^{16}$.

De un interés singular para el objeto de este estudio es el cuadro que lleva por título La casta Susana (270x203. Museo de Bellas Artes de Sevilla), en

15. Sus títulos, no convencionales, son: «La Creacion»; «Muere la materia no el espíritu»; «Los males nos circundan y abrazan»; «Descanso»; «Ayuda a tus padres»; «Perdona a tu prójimo»; «Unete a la que elegiste por compañera en la vida»; «El trabajo ilumina el camino de la fortuna»; «Haz luz que salve al inocente»; «Aparta de ti toda tentación que dañe al prójimo»; «Bendice el pan que produce la fatiga»; «La muerte no existe; todo se transforma».

16. Pérez Calero, G. Gonzalo Bilbao el pintor de las cigarreras. Madrid, 1989. Pág. 52. 
el que Gonzalo Bilbao emplea una interesante técnica a base de un cromatismo simbolista que lo acerca al usado por los pintores fauves, los cuales conceden al color su propio lenguaje simbólico ${ }^{17}$.

Al final de su vida y su obra, el autor de Las Cigarreras acomete la realización de un tríptico, presumiblemente sin terminar, cuyo título, Consolatrix aflictorum (c. 1936), hace referencia de nuevo a la iconografía mariana, pues inspirándose en el primero de los antes estudiados, escenifica en el cuerpo central a la Virgen, consuelo de los afligidos, rodeada de santas con el manto desplegado abrazando a uno de ellos, mientras un grupo de afligidos arrodillados, en su mayoría mujeres, aparece ante Ella con evidente desconsuelo. Las alas laterales representan respectivamente a los Hermanos de San Juan de Dios y las Hermanas de la Caridad atendiendo a enfermos. Se trata de un cuadro cargado de alegorías (aparecen en él representadas la Fe, Esperanza y Caridad personificadas), explicable si se tiene en cuenta que la obra fue realizada en plena contienda civil que influye notablemente en el ánimo de su autor ${ }^{18}$.

\section{EL SIMBOLISMO ALEGORICO PROFANO}

Constituye un amplio capítulo en la pintura sevillana de entresiglos, que abarca desde los mas diversos temas pictóricos (cuadro histórico, retrato...) hasta la propia cartelística, modalidad ésta que tiene en el Simbolismo su mas expresiva manifestación artística, pues el cartel constituye en sí mismo la expresión del mensaje mediante símbolos, según advierte el mismo Maurice Denis cuando, en 1920, decía que «lo importante — para el cartel- es el encontrar una silueta que sea expresiva, un símbolo que, sólo por su forma y colorido, sea capaz de atraer la atención de la multitud, de dominar al transeunte. El cartel es una bandera, un emblema, un signo» ${ }^{19}$.

Ante la imposibilidad en estos momentos de un pormenorizado estudio acerca del simbolismo en la cartelistica sevillana, objeto de un trabajo futuro, puede ahora servir de paradigma de toda ella el interesante ejemplar realizado por el pintor Francisco Narbona titulado Alegoría festiva sevillana (óleo sobre lienzo para ser ejecutado en cartel. 158x67. Prop. part.). En él están presentes varias figuras que simbolizan las fiestas primaverales de la ciudad: el angel nimbado, portador de los símbolos pasionistas, y la maja como representación iconográfica de la Feria abrileña.

El pintor Jiménez Aranda que, como se verá, también ejecuta carteles de un marcado simbolismo, realiza en 1891 varias obras en las que pueden advertirse matices propios de la tendencia estética que se estudia. Para la portada

17. Vid. nota anterior, pág. 48.

18. Vid. nota 16 , pág. 52.

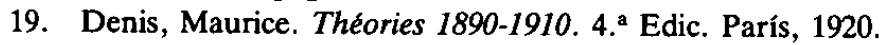


de la Revista del Círculo de Bellas Artes de Madrid realiza una aguada (67x49. Prop. part.) en la que representa una hermosa muchacha semidesnuda subida a un altísimo y monumental pedestal que lleva el escudo de la institución, desde el que se inclina hacia el vacio para lanzar al viento multitud de ejemplares de la revista. Al fondo se divisa un espléndido paisaje del que destacan esbeltas torres con chapiteles y pináculos alusivos al viejo Madrid de los Austrias.

El año anterior, el pintor sevillano había realizado un interesnate dibujo para la cabecera del libro del crítico Augusto Comas: «La Exposición Nacional de Bellas Artes de Madrid de 1890», en el que igualmente representa la figura simbólica de la anterior modelo (¿una de sus hijas?) sentada al aire libre ante el caballete y apoyado el antebrazo derecho sobre una carpeta de dibujos, junto a la que se halla una caja abierta de pinceles. La obra - su mismo título lo indica: Plein Air - simboliza la modalidad pictórica puesta en boga en España por los paisajistas a partir de la llegada del belga Carlos de Haes (1955-7) y en la que Francia, de la que precisamente acababa de regresar J. Aranda, ocupa el papel de difusora.

Por entonces, el mismo pintor hispalense, ejecutó el retrato de su hija Rosa (65x52. Prop. part.) quien, recien fallecida y por la que sentía un entrañable amor paternal, efigió con nimbo sobre la cabeza, lo que proporciona al retrato un particular sentimiento de idealización simbolista, determinado además por el tratamiento luminoso del espacio que envuelve la figura creando un ambiente especialmente lírico cuasi poético ${ }^{20}$.

Entre las últimas obras de Jiménez Aranda se cuentan varias correspondientes al cartelismo, en las que agota la senda del simbolismo iniciado apenas dos décadas antes. Ahora, se hace presente, además, con mayor fuerza un determinado modernismo que afectó también al cartel sevillano ${ }^{21}$.

El ejemplar de 1903 (253x117), anunciador de las fiestas locales de primavera y encargado por el Municipio al pintor, muestra, junto a la heráldica de la ciudad, flores de la primera estación del año, entre la que destaca la primorosa figura de una alegre y hermosa joven ( $¿$ acaso el retrato de una de las hijas del pintor?) que generosa derrama por el cuerno de la abundancia que porta - como si de una Fortuna hispalense se tratase- los motivos de las alegres fiestas de la ciudad 22 .

Un año antes, el mismo artista había ejecutado un dibujo a color que bajo el título de La Caridad fue realizado para el Festival Benéfico de Caridad en Cádiz de 1902, luego reproducido en tarjetas postales. Representa simbólicamente varias manos extendidas para recibir la limosna de una anónima señora de la que solo se ve su mano bienhechora ${ }^{23}$.

\footnotetext{
20. Vid. nota 3, pág. 108-109.

21. Mateos de los Santos Pérez, G. Un siglo de carteles festivo-religiosos en Sevilla (1881-1987). Sevilla, 1988.

22. Vid. nota 3, pág. 63 .
} 
El pintor Virgilio Mattoni, al que vimos cultivando un interesante simbolismo religioso, aborda también el cuadro alegórico-profano de connotaciones simbolistas muy acusadas, en algunos de los cuales incluye también elementos modernistas en su variante "Estilo 1900», pese a su aparente aversión al movimiento ${ }^{24}$. Esta tendencia del pintor hacia una estética que se distancia cada vez mas del Realismo decimonónico en busca de una determinada abstracción pictórica, que en ocasiones nada menos que parece querer rozar el Surrealismo, es valorada por el propio Salvador Dalí, quien, «se pasa buena parte del día indagando el significado profundo de un cuadro que él descubrió, años atrás, con solo posar en él los ojos. Las postrimerias de San Fernando lleva por título; se halla en el Museo de Sevilla y su firma corresponde al andaluz Virgilio Mattoni. Me muestra la reproducción fotográfica del amplio lienzo en el que el rey santo aparece en trance de recibir su última Comunión, y, seguro de su profecía sin plazo, exclama: Este cuadro debe acompañar a los de Gala en las vallas de las ciudades. En su flanco derecho, al igual que los otros, llevará esta leyenda: ¡Abrid los ojos! Va a empezar la nueva vanguardia en pintura. Dalí. Un mirar hacia atrás para seguir adelante» ${ }^{25}$.

De fines de siglo (1899) es la acuarela mattoniana que lleva por título iJerez por «el Jerez»!! presumiblemente un pequeño estudio para cartel $(61 \times 30$. Prop. part.). En él están presentes determinados valores simbolistas propios del lenguaje publicitario que comporta la obra. Muestra a una joven graciosa y desenvuelta que ante un barril y junto a una guitarra brinda con una copa del famoso vino.

El retrato de Dolores de Guzmán y el cuadro titulado Los amantes y la neblina son, sin duda, las mas interesantes obras simbolistas alegórico-profanas del pintor sevillano. En ambas, como hacía Gustavo Moreau, pinta angeles viajeros o figuras semejantes que parece querer posarse momentáneamente en lo alto de un campanario gótico. El primero $(26 \times 15 \mathrm{~cm}$. Prop. part.) fechado el 6 de mayo de 1900, supone una pieza antológica en la producción del artista por su decidida vinculación al Simbolismo modernista dentro del llamado «Estilo 1900». Emplea elementos iconográficos que así lo evidencian: angel volador portando una cornucopia en donde se incluye a la retratada en elegante vuelo sobre el mar en serena y estrellada noche iluminada simbólicamente por un romántico plenilunio ${ }^{26}$.

En el segundo cuadro mencionado (130x60 cm. Prop. part.), de ciertas connotaciones goyescas, emplea, como también a veces hace Odilon Redon, una gama cromática muy oscura para crear el determinado climax, cual si de gri-

23. Domínguez Valero, E.F. «La tarjeta postal en España. Del Modernismo al Art Deco». «Antiquaria». N. ${ }^{\circ}$ 53. Madrid, 1988. Pág. 34.

24. Vid. nota 5.

25. Amón, Santiago. « ¡iva la Gala! Entrevista con Dalí». «A.B.C.». Madrid, 23/4/1985. Pág. 10.

26. Pérez Calero, G. «Gonzalo Bilbao y la Pintura del regionalismo en Sevilla». Catálogo de la Exposición «Gonzalo Bilbao y la Pintura sevillana de su tiempo». Sevilla, 1988. Pág. 9. 
salla se tratase, propiciando la atmósfera adecuada que acentúa unos caracteres simbolistas visionarios - cuasi surrealistas- en que se desarrolla la «etérea» escena (¿un sueño de verano?): dos amantes fundidos en un ardiente beso, representados como dos lenguas de fuego que ascienden, cual sendas ráfagas de viento, por entre los contrafuertes y pináculos góticos de la catedral hispalense, mientras son contemplados en la parte inferior por el diablo que gesticula furioso ante tal espectáculo de amor humano.

También, el mismo Villegas y Cordero hace suya la moda simbolista en cuadros profanos en los que no faltan los consabidos convencionalismos iconográficos ya mencionados a propósito de El Decálogo. En algunos de ellos, se evidencia la tendencia del maestro sevillano hacia el costumbrismo al que pertenece por generación y que le lleva por un determinado anecdotismo. Sin embargo y pese a esto último, en el mejor de todos ellos titulado, Sevilla dio siempre luz y esplendor (paradero actual desconocido), realizado en 1908, su autor se mantiene dentro de su personal iconografía simbolista caracterizada por los efectos ilusionistas y fantásticos; así, los producidos por la luz en su incidencia violenta sobre personajes y objetos. Cuadro apaisado, escenifica el anagrama de Sevilla «NO\&DO» que, en torno a un impresionante halo luminoso, refleja su poderío mediante la virtud y el mérito que se proyectan, al ser lanzados por una esbelta y bellísima figura, sobre un personaje femenino que sentado en un pedestal clásico porta en su mano derecha una palma que ofrece a la anterior, y lleva sobre su regazo una cinta con la leyenda «La Real Maestranza de Caballería de Sevilla». A su espalda aparece el cuerpo de campanas de la Giralda envuelto en una luz irreal y en su entorno multitud de hojas que llevan inscritos nombres de personajes de la cultura y el arte sevillanos ${ }^{27}$.

Finalmente, conviene siquiera mencionar algunas otras obras de Villegas en las que manifiesta matices simbolistas, entre ellas las tituladas: El baño de Corinto; El triunfo de la joven América y Las tres gracias de Sevilla.

Como epílogo de esta visión general del simbolismo en la Pintura sevillana de entresiglos y prueba de hasta que punto calo, siquiera de forma efímera, en el hacer de los artistas mas representativos de la misma, es interesante estudiar una de las últimas obras del costumbrista José García Ramos (18521912) titulada Ninfas, propiedad del Real Círculo de Labradores y Propietarios de Sevilla.

Fechable en la primera decena del siglo, se trata de una suerte de tríptico muy decorativo por su aire modernista, en el que se representa una escena mitológica cargada de simbolismo por sus alusiones a todo un mundo mágico pletórico de fantasía. En él, no está ausente cierta sensualidad erótica propiciada por toda clase de efectos luminosos y espectaculares en relación con el

27. Pérez Calero, G. «La iconografía simbolista del pintor José Villegas». Comunicación del II Coloquio de Iconografía. Madrid, 1990. En vías de publicación. 
agua como elemento que juega coquetamente con las ninfas marinas. De entre ellas destaca, en el centro, dentro del tondo, la representación probablemente de Venus o, tal vez de Tetis, la mas hermosa de las nereidas cuidadoras de Apolo.

Como en ésta última, el Simbolismo hispalense propende al contenido mágico o espiritual. Busca expresar lo aparentemente inexpresable mediante modos exquisitos y sutiles, a veces no bellamente expresado, e incluso en ocasiones difícilmente comprensible. 


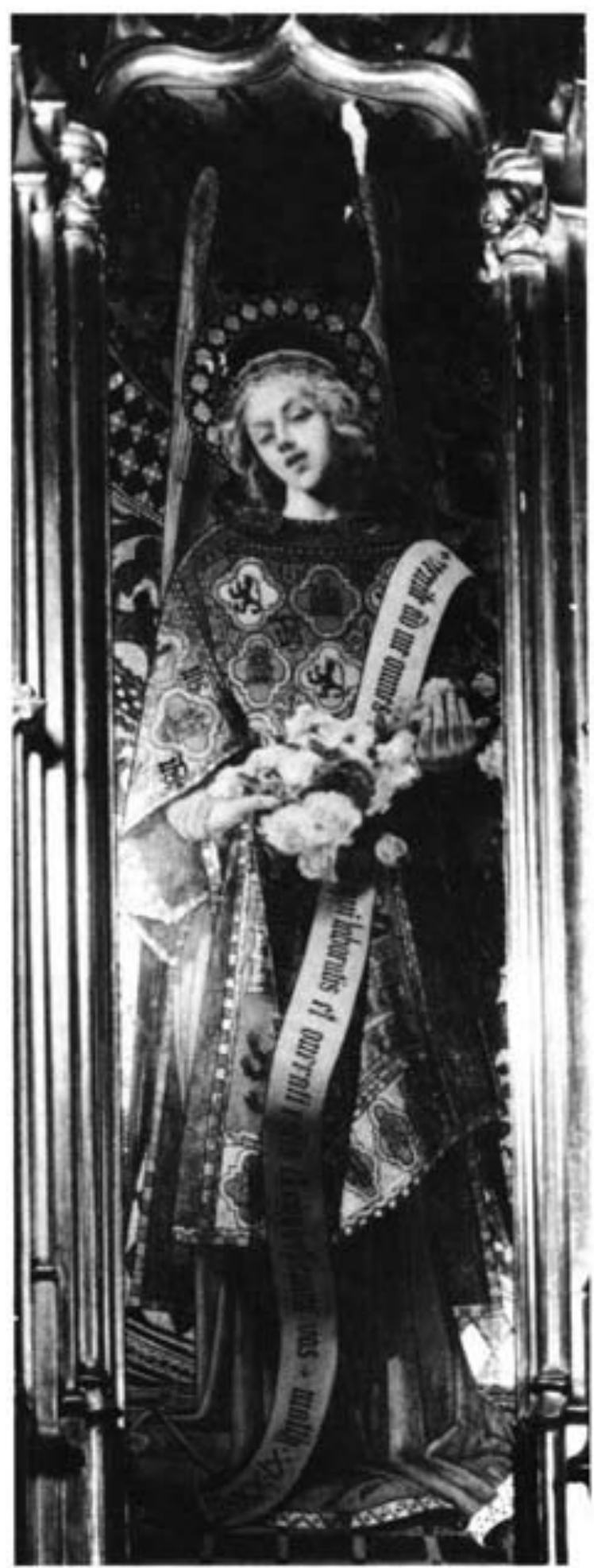

Lamina I

V. Mattoni. Angel heráldico. 1893. Capilla del Sagrado Corazón de Jesús en la iglesia parroquial de San Andrés de Sevilla. 


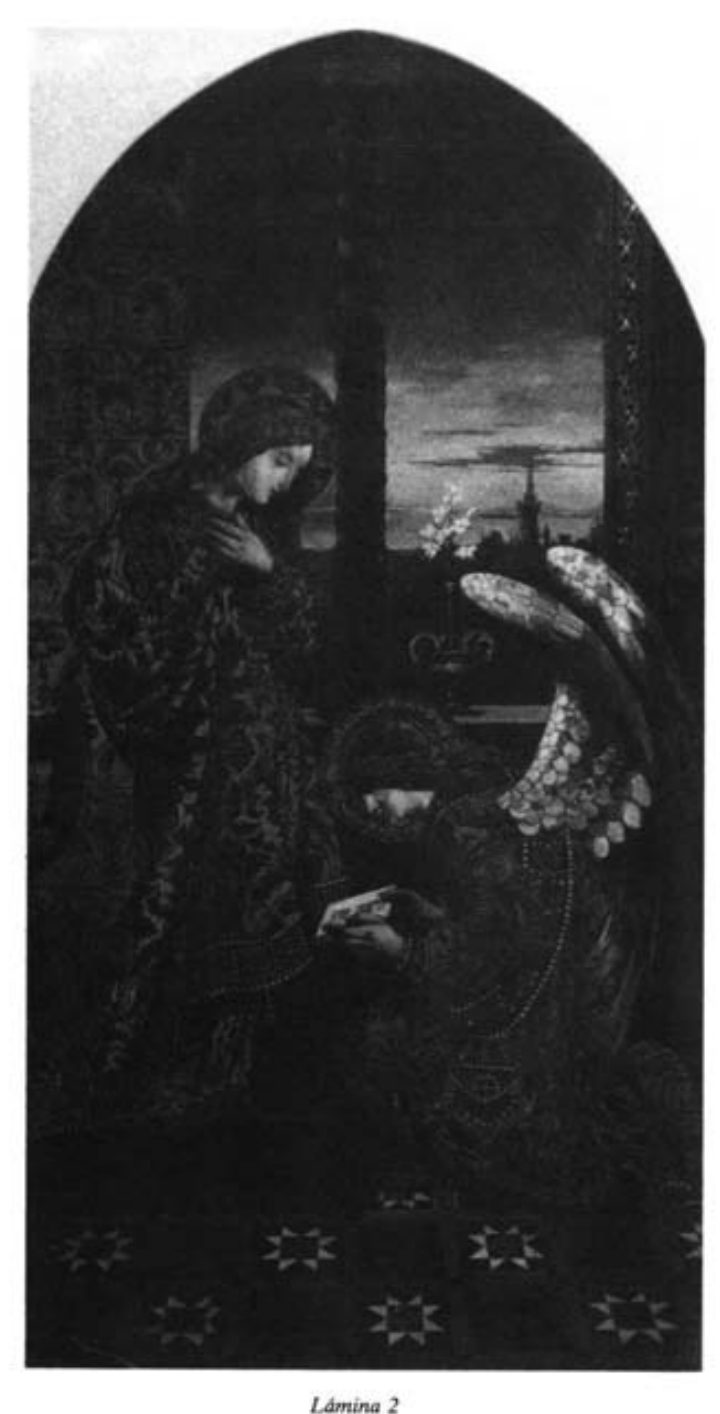

V. Mattoni. Anunciación. (1987). Catedral de Sevilla. 


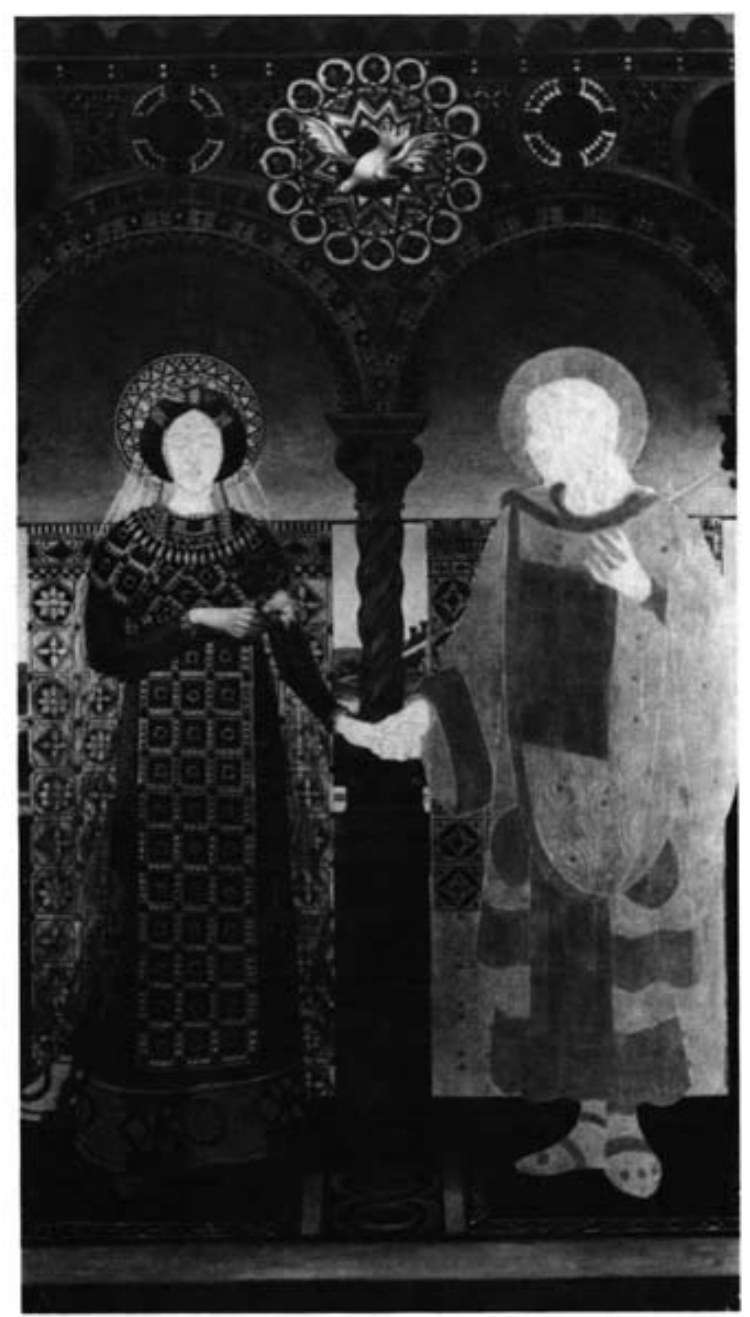

Lamina 3

v. Mattoni. Desposorio mistico. S/d. Prop, part. Sevilla. 


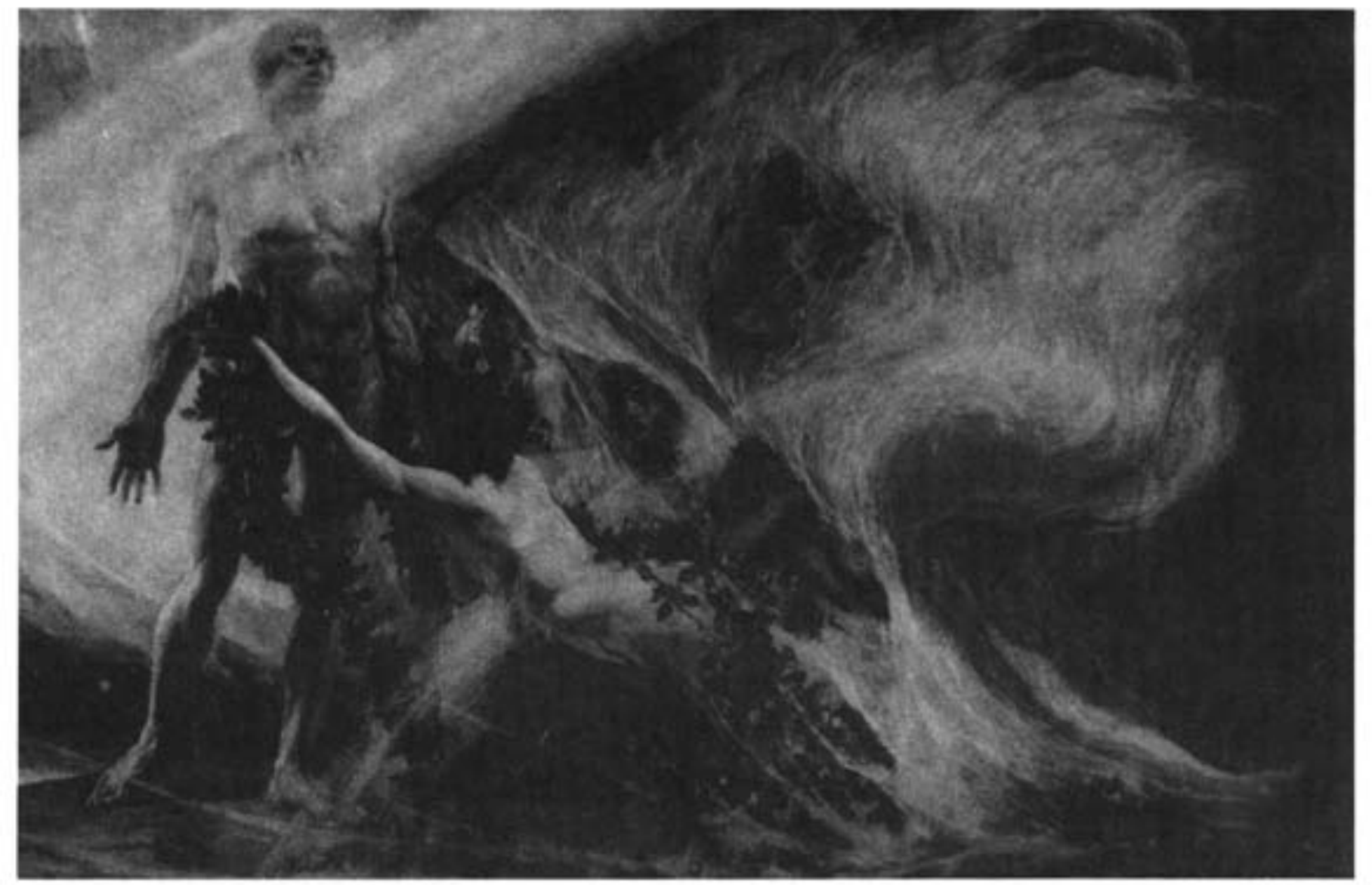

Lamina 4

J. Villegas y Cordero, -Los males nos circundan y abrazan-. $2 .^{\circ}$ mandamiento del "Decalogow. Prop. part. 


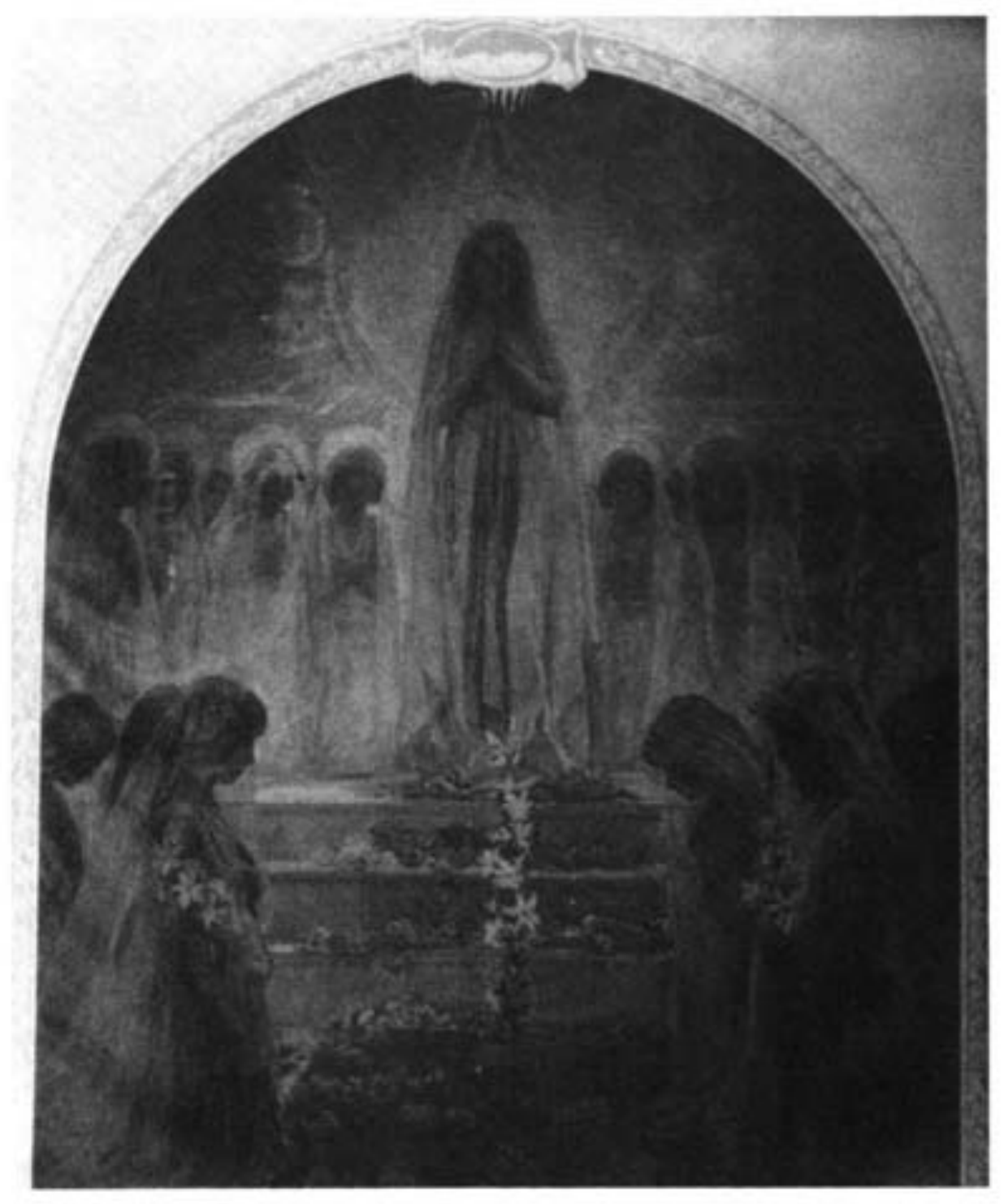

Lámina 5

G. Bilbao Martínez, Regina Virginum (1902).

Protectorado de la Infancia. Sevilla. 


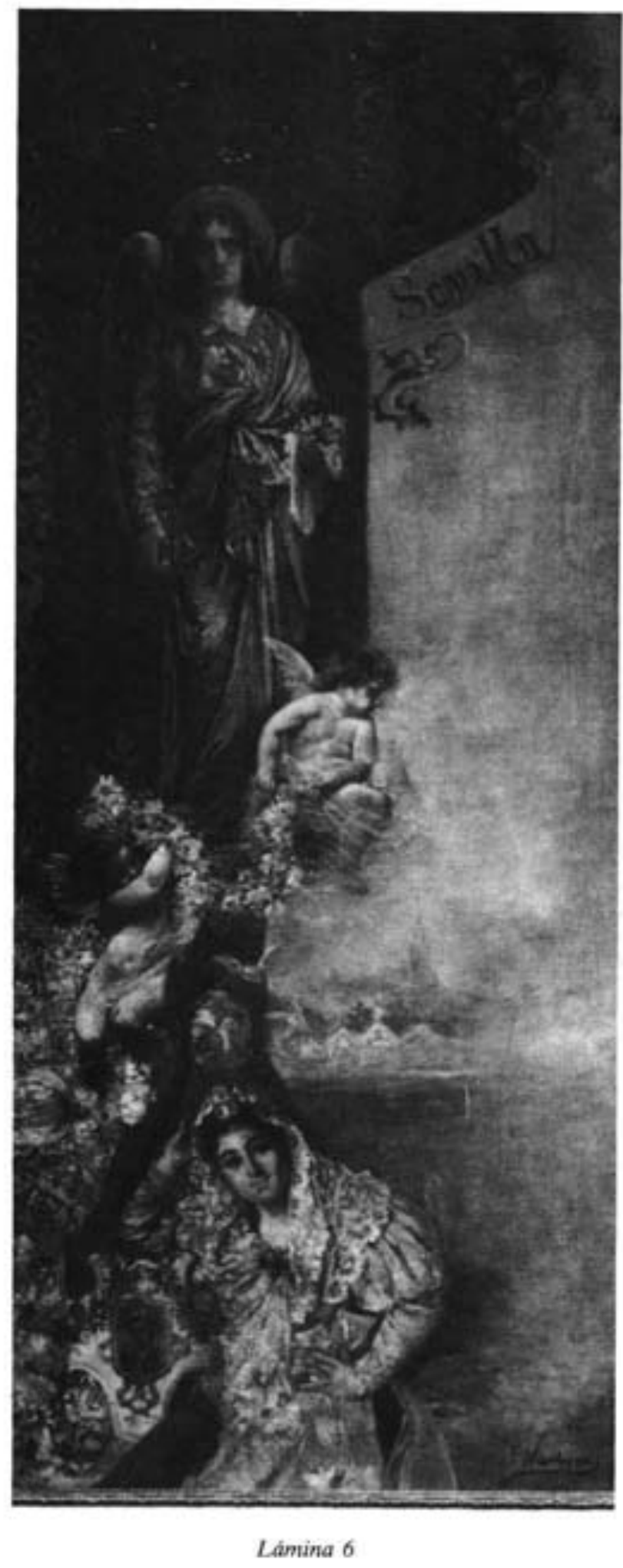

Francisco Narbona. Alegoria festiva sevillana, S/d. Prop. part. 


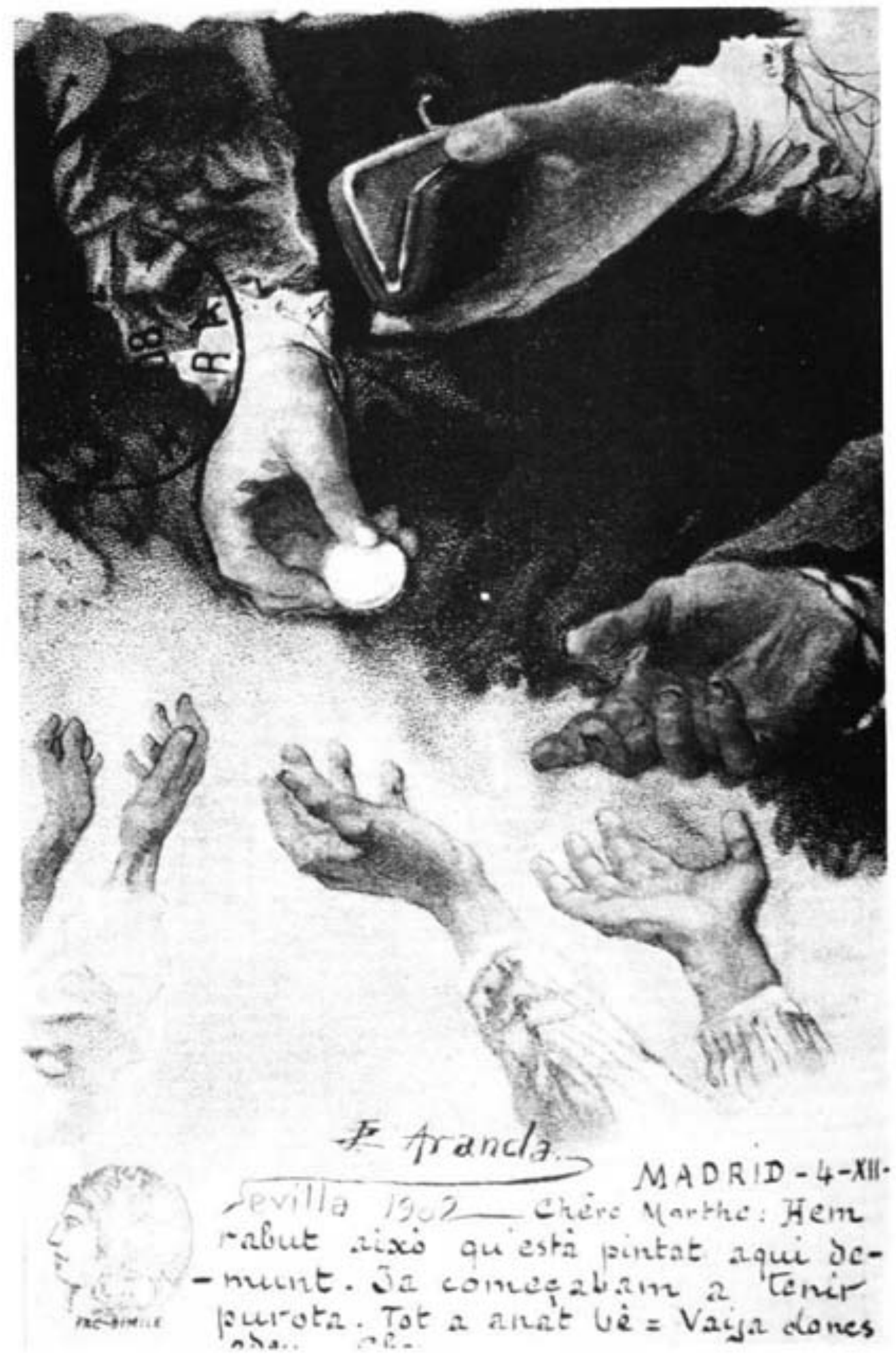

Lamina 7

J. Jiménez Aranda. Tarjeta postal para el festival gaditano de la Caridad. (1902). 


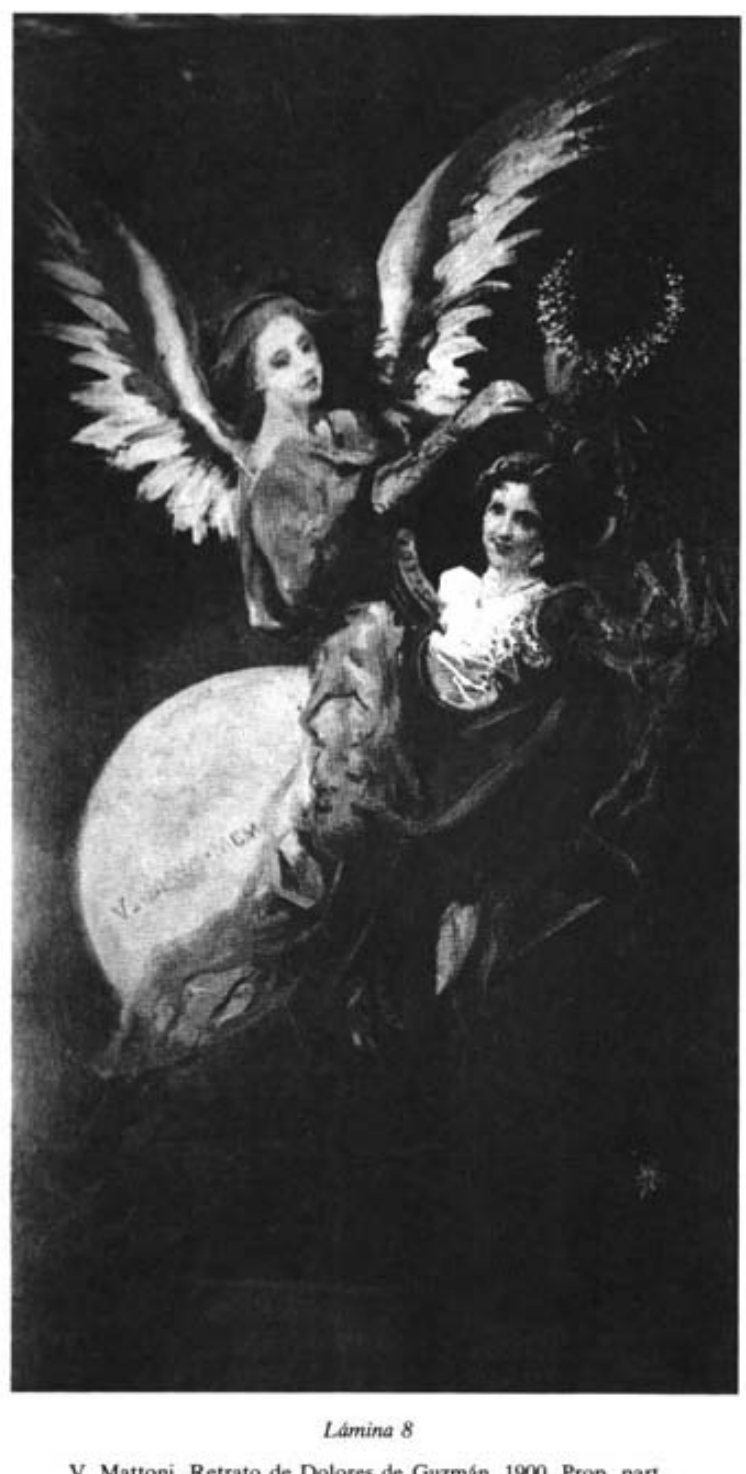

V. Mattoni. Retrato de Dolores de Guzmán. 1900. Prop. parn. 


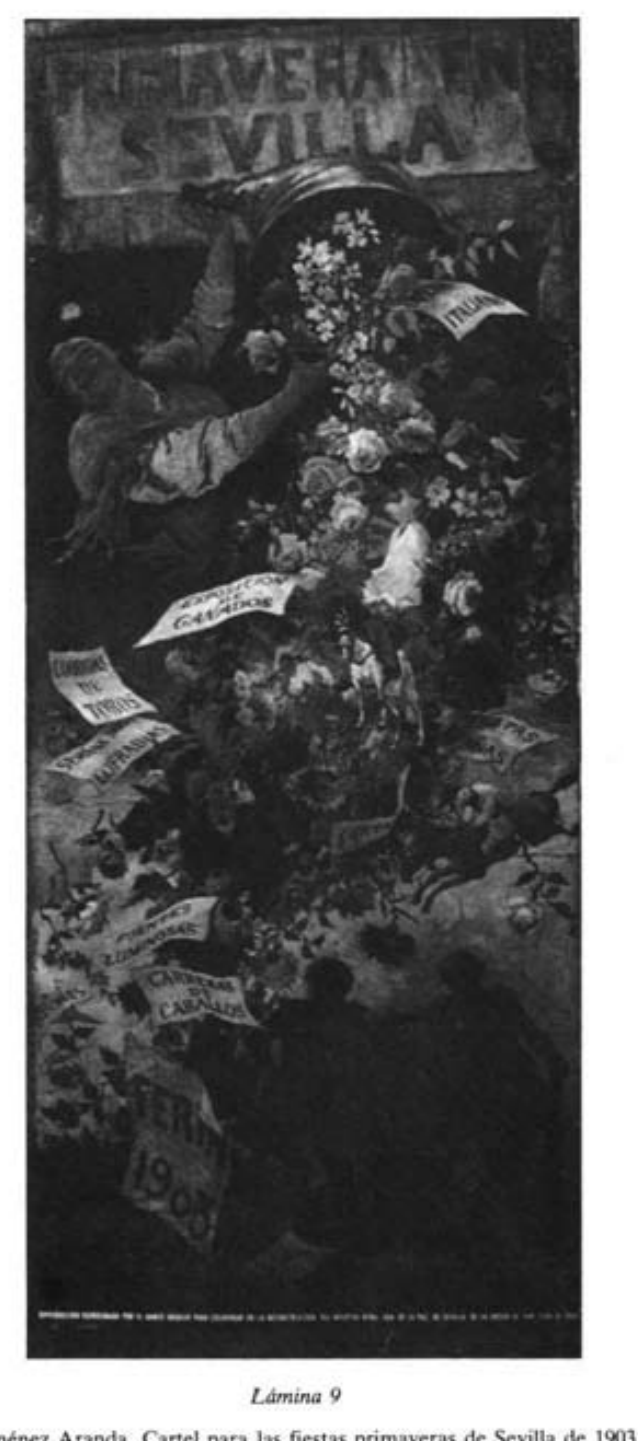

J. Jimenez Aranda. Cartel para las fiestas primaveras de Sevilla de 1903. 


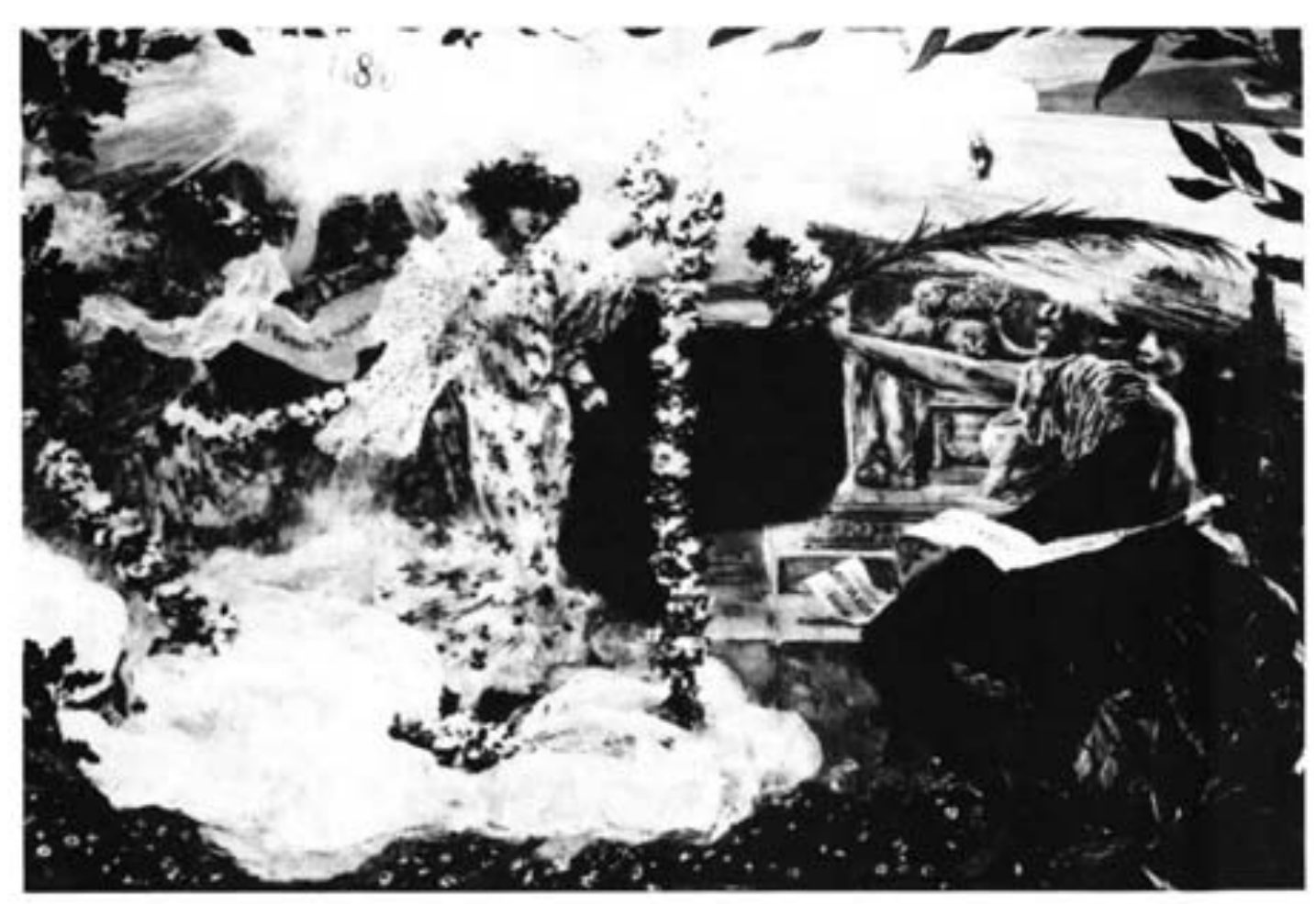

Lamina 10

José Villegas. -Sevilla dio siempre luz y esplendor». 1908. 